\title{
DAMAGE IN FIBRE-REINFORCED LAMINATES UNDER DYNAMIC LOADING
}

\author{
H. Ullah, G. Tsigkourakos, F. Vartzopoulos, I.A. Ashcroft, V.V. Silberschmidt* \\ Wolfson School of Mechanical and Manufacturing Engineering, Loughborough University, \\ Leicestershire, LE11 3TU, UK \\ *Corresponding author (V.Silberschmidt@lboro.ac.uk)
}

\begin{abstract}
Fibre-reinforced polymers (FRPs) became one of the most important structural materials in various industries due to their unique combination of properties such as excellent stiffness, high strength-to-weight ratio, and ease to manufacture shapes tailored for applications. Hence, they are now broadly used in aerospace and naval structures as well as in automotive, construction and energy industry; there is an increasing use of them in sports products. In service, components and structures, containing composites, can be exposed to different loading conditions including dynamic events, e.g. impacts. Such loads can cause deterioration of their structural integrity and load-bearing capacity due to induced damage. Because of their heterogeneity and microstructure, composite laminates usually demonstrate multiple modes of damage and fracture if compared with more traditional, macroscopically homogeneous, structural materials such as metals and alloys.
\end{abstract}

This study deals with analysis of damage in two types of fibre-reinforced polymers cross-ply and woven laminates - under impact loading. The first type of FRP is exposed to conditions of impact fatigue (IF). IF can be defined as a repetition of low-energy impacts with energy amplitudes insufficient to cause a total failure of a component in a single impact. Another type of laminate - reinforced with 2/2 twill fabric - was loaded in various modes.

The properties of, and damage evolution in, the studied two types of laminates were analysed using a combination of mechanical testing and microstructural and damage studies using optical microscopy and X-ray micro computed tomography. Dynamic mechanical tests on cross-ply laminates were implemented using a uni-axial tensile impact loading. Advanced FE models were developed in Abaqus/Explicit to characterise the response of FRP laminates to impact loading conditions in order to elucidate their dynamical mechanical behaviour. A $3 d$ finite-element model for uni-axial tensional impact loading of tested samples of FRP cross-ply laminates was developed with a hammer-specimen interaction simulated directly to obtain detailed information about impact conditions. The obtained results are compared with experimental data.

Keywords: FRP, dynamic loading, impact, damage

\section{INTRODUCTION}


Fibre-reinforced composites such as carbon fibre-reinforced polymers (CFRPs) are widely used in aerospace, automotive and construction structures due to their high specific strength and stiffness. Woven-fabric composite laminates offer a number of attractive mechanical properties compared to their unidirectional-tape counterparts such as good resistance to fracture and transverse rupture due to weaving resistance and high impact strength [1]. These properties have attracted the sports industry to incorporate woven CFRP laminates in the design of sports products that could be subjected to large-deflection bending and multiple impacts in service conditions. This type of quasi-static and dynamic loads generate high local stresses and strains leading to complex damage modes due to heterogeneity and anisotropy of composite laminates. Composite structures suffer more damage as a result of impact than similar metallic structures. The damage mechanisms typically caused by out-of-plane impact loads in laminates are matrix cracking, fibre breakage and delamination at interfaces within the composite structure [2]. Impact damage and, in particular, delamination occurring at low-velocity impact cause a significant decrease in the material's in-plane compressive strength and stiffness. Such internal damage mechanisms that often cannot be detected by visual inspection degrade the load-bearing capacity of the structures. Therefore, it is important to study the damage suffered by the composites under impact loading conditions.

Apart from the impact study of woven CFRP laminates, an impact-fatigue behaviour of cross-ply CFRP laminates is also investigated in this manuscript. A reason for multiple lowenergy impacts (known as Impact Fatigue (IF)) in laminates could be, for instance, wind gusts during a flight. IF can be defined as a repetition of low-energy impacts with energy amplitudes insufficient to cause a total failure of a component in a single impact [3]. The effects of IF and their detrimental effect on the structural integrity of components can be observed after relatively few impacts, even at force amplitudes significantly lower than the durability limit in a standard fatigue regime [4]. Up to now IF was not accounted in designing of composite structures for service life. The method that is being used for years to predict the service life is standard- fatigue (SF) analysis, e.g. the rainflow algorithm in combination with the Miner's rule. However, sharp stress peaks caused by IF observed in the stress spectrum are treated as SF data, which could result in wrong estimation of fatigue life.

The low-velocity impact response of woven-fabric composite laminates has been extensively treated in the literature employing experimental studies, analytical formulations and numerical implementations. Abrate [5] analysed dynamics of impacts using an analytical approach based on energy-balance and spring-mass models. Naik et el. [6] studied the behaviour of woven-fabric composite plates under transverse low-velocity impact with an analytical model based on a modified Hertz law and a 3D numerical model. Johnson et al. [7] presented a material failure model for composites with fabric reinforcement under impact loading, which included both intra-ply damage and plasticity based on continuum damage mechanics approach, and inter-ply delamination. Iannucci and Willows [8] presented an energy-based damage mechanics model and interface modelling technique for woven carbon composites under high-strain dynamic loading employing an explicit FE code. Reyes and Sharma [9] studied experimentally and numerically a low-velocity impact damage behaviour of woven GFRP laminates under various levels of impact energies. However, majority of 
these studies are dedicated to the impact behaviour of composites tested with instrumented drop-weight impact towers, which usually caused localised damage such as penetration and perforation in impacted laminates. A large-deflection dynamic bending behaviour of laminate composites caused by a pendulum-type impactor is rarely investigated. In this connection, the authors studied earlier a large-deflection behaviour of woven laminates under quasi-static bending and tensile loads [10-12]. Investigation of impact-fatigue behaviour of CFRP composites has received little attention to date. In this regard few studies can be found (e.g. Silberschmidt et al. [13] and Casas-Rodriguez et al. [3, 4]) where an instrumented impactor was used to study damage in adhesively bonded CFRP joints under repeated impacts; the loading mode was tensile there.

In the present work, a large-deflection bending behaviour of woven-fabric CFRP laminates subjected to impact loads is studied. Flexural impact tests were carried out using a pendulum type impact tester at various energy levels. The type and location of damage were investigated with optical microscopy. A multi-body-dynamics impact finite-element model was developed in Abaqus/Explicit for both undamaged and damaged specimens. The obtained modelling results have good agreement with our experimental data. Additionally, an impactfatigue behaviour of cross-ply laminates is studied under uni-axial tensile dynamic loading conditions, a unique testing system at Loughborough University, capable of subjecting specimens to uni-axial tensile dynamic loading. In experiments, CFRP cross-ply specimens with a central hole were subjected to multiple impacts and the damage initiation and propagation around the hole was examined. Effects of damage on the fatigue life were assessed with X-ray micro-CT and the use of a load-time model. Numerical models developed in Abaqus/Explicit, which utilised cohesive-zone elements (CZEs), served the purpose of validating the experimental results.

\section{EXPERIMENTAL METHODS}

\subsection{Specimen Preparation}

Two types of woven and cross-ply CFRP laminates were tested to obtain their material parameters. Woven CFRP specimens were prepared from laminates of woven fabric made of carbon fibres reinforcing a thermoplastic polyurethane (TPU) polymer matrix. The fabric was produced from $0^{\circ} / 90^{\circ}$ prepregs in the form of four plies designated as $\left[0^{\circ}, 90^{\circ}\right]_{2 s}$, where $0^{\circ}$ and $90^{\circ}$ represent yarns in the warp and weft directions, respectively. The woven laminate had a $2 / 2$ twill weaving pattern with a fibre volume fraction of $45 \%$; the fabric had the same number of yarns in the warp and weft directions. Un-notched rectangular specimens of $40 \mathrm{~mm}$ length, $25 \mathrm{~mm}$ width and $1.0 \mathrm{~mm}$ thickness (each laminate had four layers of $0.25 \mathrm{~mm}$ thickness) were prepared. Before dynamic testing, both side edges of the specimens were polished to a scratch-free surface finish with the aid of $3 \mu \mathrm{m}$ and $1 \mu \mathrm{m}$ diamond spray on DUR cloths.

Cross-ply CFRP samples were made using a uni-directional carbon/epoxy T700/LTM45 prepreg with a nominal ply thickness of $0.128 \mathrm{~mm}$; T700 fibre is used in the wings and the 
fuselage of airplanes due to its high strength. LTM45 is a toughened, low-temperature curing epoxy resin capable of high-temperature end use. The composite system T700/LTM45 (from Advanced composite Group ACG), was mainly selected because it can be easily cured at low temperature and its mechanical property data were available at Loughborough University. Its UD mechanical properties, measured at Loughborough University, are displayed in Table 1. Two cross-ply lay-ups of $0_{2} / 90_{4} / 0_{2}$ and $0_{4} / 90_{8} / 0_{4}$ (we use here different notation for lay-ups to differentiate between the composite types) were selected, as that enabled a number of failure mechanisms and the effect of doubling the thickness on the fatigue life to be investigated in a relatively simple system. Similarly, elastic material parameters determined from tests in the warp, weft and shear directions for woven CFRP specimens are also presented in Table 2.

Table 1. Properties of T700/LTM45 composite at room temperature

\begin{tabular}{cccccc}
\hline $\begin{array}{c}E_{11} \\
(\mathrm{GPa})\end{array}$ & $\begin{array}{c}E_{22}=E_{33} \\
(\mathrm{GPa})\end{array}$ & $\begin{array}{c}G_{12}=G_{23} \\
(\mathrm{GPa})\end{array}$ & $\begin{array}{c}G_{13} \\
(\mathrm{GPa})\end{array}$ & $v_{12}=v_{13}$ & $v_{23}$ \\
\hline 127.0 & 9.1 & 5.6 & 4.0 & 0.31 & 0.4 \\
\hline
\end{tabular}

\subsection{Experimental procedure}

\subsubsection{Impact tests of woven CFRP laminates}

Dynamic impact tests were carried out on an instrumented pendulum-type CEAST Resil impactor according to ISO 180 standard. In the impact tests, the bottom of the specimen was fixed firmly in the machine vice as a cantilever beam. The upper $30 \mathrm{~mm}$ of the specimen was struck by the striking nose of the pendulum hammer with a controlled level of energy, resulting in dynamic large-deflection bending. The distance between the fixed support and the line of contact of the hammer's striking nose was kept at $22 \mathrm{~mm}$ according to the standard. In this work, a calibrated impact hammer with a mass of $0.6746 \mathrm{~kg}$ and $0.3268 \mathrm{~m}$ length was used. The hammer can generate an impact of maximum energy of $2 \mathrm{~J}$ at impact velocity of $3.46 \mathrm{~m} / \mathrm{s}$ corresponding to the initial angle of $150^{\circ}$ to the striking position. The magnitude of initial impact energy and velocity can be varied by changing the initial angle of the hammer. CFRP specimens were tested at various energy levels to determine the energy inducing the ultimate fracture of the specimen. It was found that the specimen fractured at $0.6 \mathrm{~J}$ corresponding to the initial angle of $64^{\circ}$. The rest of the tests were carried at $0.5 \mathrm{~J}$ corresponding to $58^{\circ}$ to study the behaviour of sub-critical damage modes such as matrix cracking and delamination. A piezoelectric force transducer was fixed rigidly to the hammer striking nose to capture the impact force signal. After the pendulum hammer is released from the pre-defined initial angle, the impact with the specimen generates a change in electrical resistance of the piezoelectric sensor that is captured by the data - acquisition system - DAS 8000 - connected to the Resil impactor. The signal is registered with a pre-defined sampling frequency of $833 \mathrm{kHz}$, with up to 8000 data points recorded per impact test. In order to 
decrease the data noise a $1 \mathrm{kHz}$ filter was used in our tests. Typical records of force vs. time for un-fractured and fractured CFRP specimens are presented in Figure 1. Although the unfractured samples underwent interlaminar damage before the structure lost its load-carrying capacity, the development of such inter-ply delamination did not provide visible signs of it in the force-time plot for $0.5 \mathrm{~J}$ (Fig. 1).

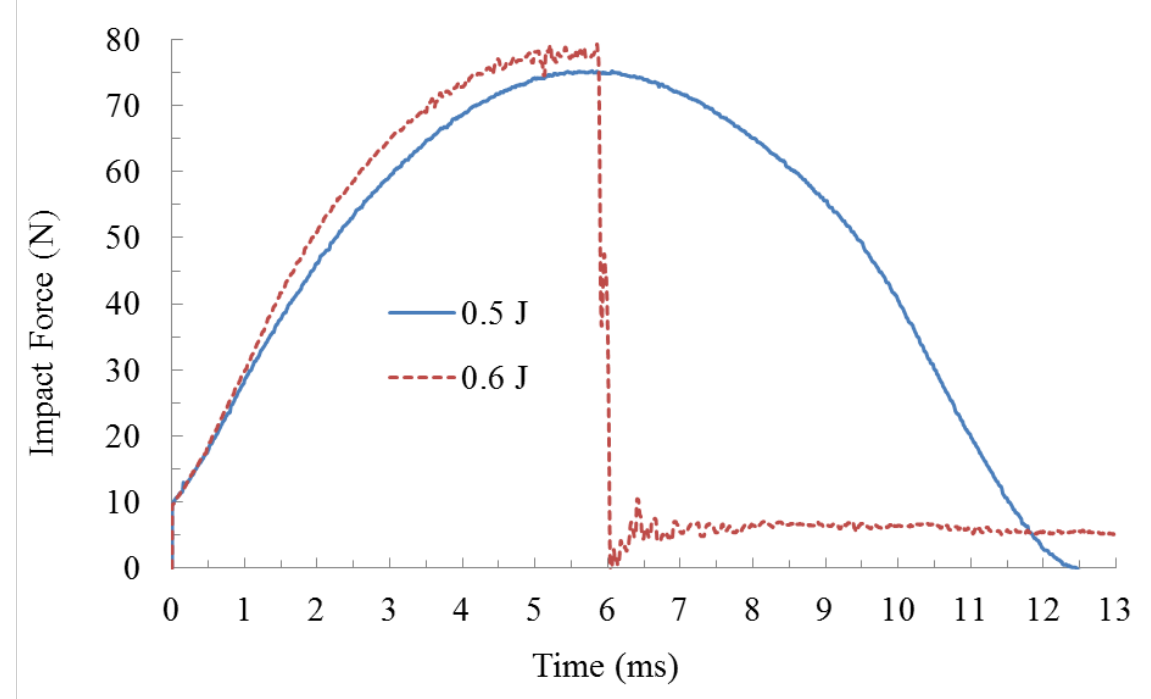

Figure 1. Force-time response of twill 2/2 woven CFRP laminate in impact tests with different energy levels

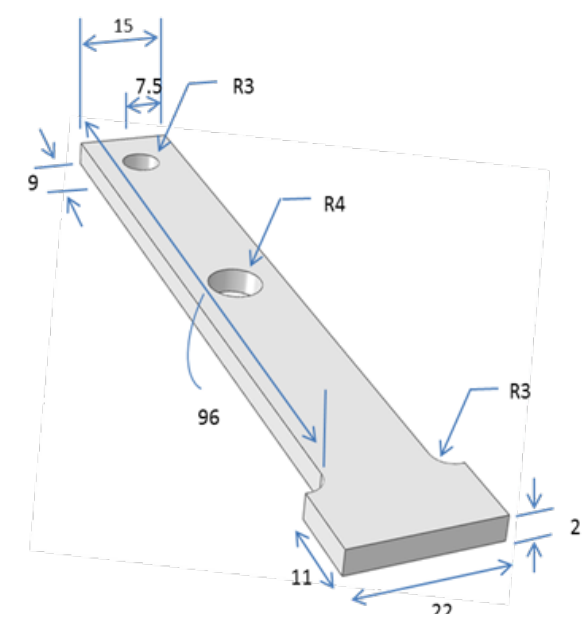

Figure 2. Schematic and dimensions of specimen used in uniaxial impact tests (Dimensions are in millimetres)

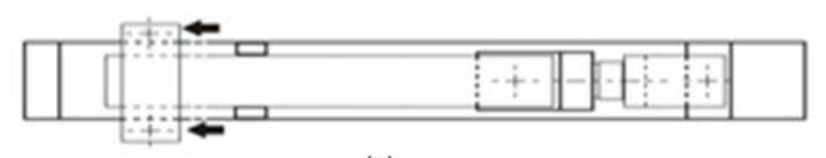

(a)

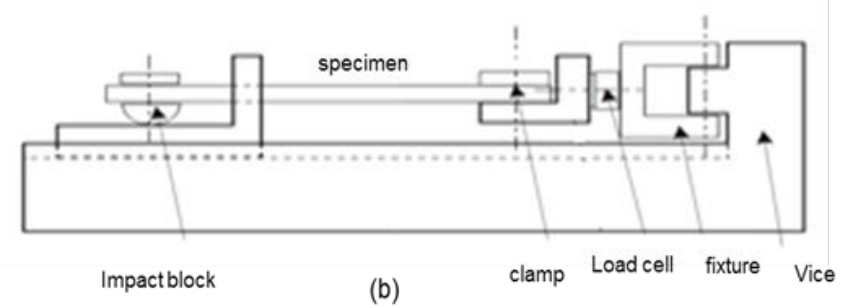

Figure 3. Schematic of specimen fixture for impact fatigue. (a) Top view, arrows denote impact loading direction, (b) Side view

CFRP specimens were subjected to impact energies of $0.5 \mathrm{~J}$ and $0.6 \mathrm{~J}$ using an instrumented pendulum impact hammer. Figure 1 shows the variation of load with time for both energy levels. At the energy level of $0.5 \mathrm{~J}$, the loading and unloading curve has a nearly symmetric parabolic shape suggesting that the respective stages during the contact duration are almost the same and no significant damage has occurred. The maximum impact force at 
0.6 J energy, causing the specimen's ultimate fracture, is higher. Here, a higher impact energy induces larger deformation and therefore, larger impact force. The respective load-time graph in Figure 1 shows oscillations due to significant damage inside the specimen before its ultimate bending fracture. The ultimate fabric fracture is represented by the sudden drop in contact force implying a momentary loss of contact between the impactor and specimen.

\subsubsection{Impact-fatigue tests of cross-ply CFRP laminates}

Cross-ply CFRP specimens were tested to analyse fatigue crack growth under repeated uniaxial tensile impacts. The specimen's configuration, as shown in Figure 2, was adopted in conformity with BS EN ISO8256:2004, with modification to fit the tensile impact machine, as shown in Figure 3. Those specimens were impacted 33000 times to the state where intra-ply damage occurred, and the force vs. time data was recorded for a set of cycles, as shown in Figure 4. The presented force-time responses were selected at the initial life of the specimen (10 impacts), its half-life (16500 impacts), and 33000 impacts (total life). From the graph below it can be seen that the maximum force response remains practically the same for those three stages, while the time required for the force to vanish increasing continuously. This trend will be analysed in terms of damage formation in the specimen; hence, $\mathrm{X}$ - ray micro-CT analysis was undertaken.

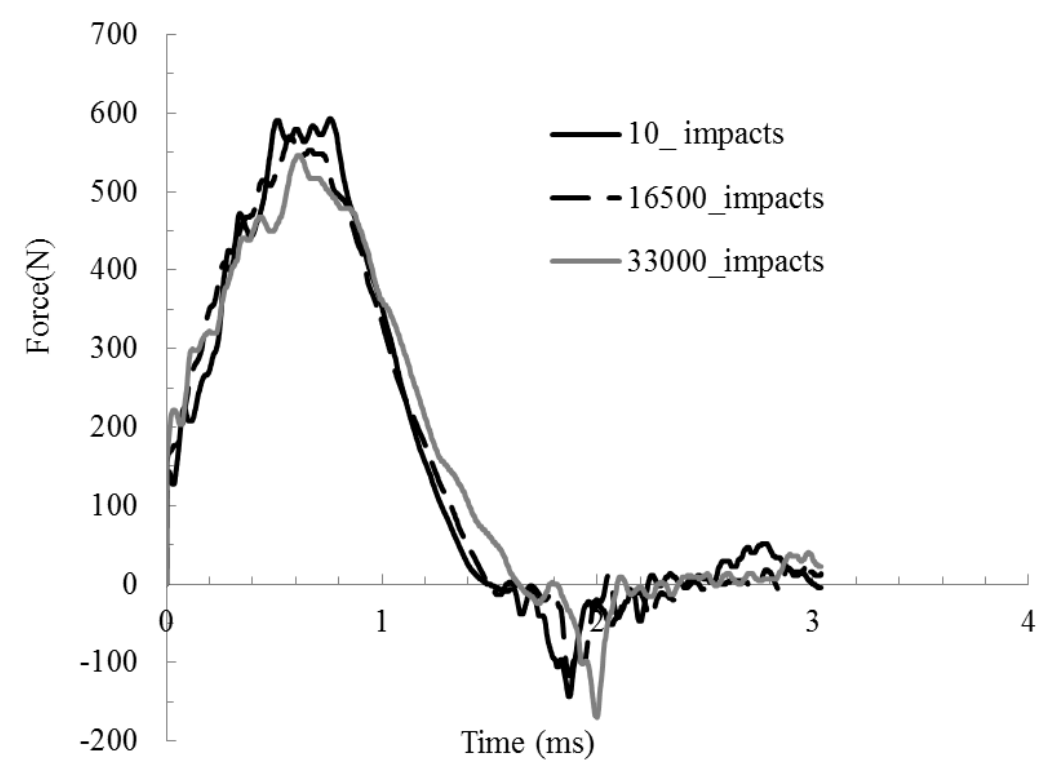

Figure 4. Force $v s$. time response in various cycles of impact-fatigue life

\subsection{Microscopic analysis of woven CFRP}

Microscopic analysis of composite specimens is a suitable technique for evaluation of damage in woven-fabric laminates. In order to visualize the type and location of damage, microscopic analysis allows for the study of the comprehensive damage behaviour of 
composite specimens. This technique was also employed in [14] for damage characterisation of woven CFRP laminates. In this work, an OLYMPUS BX-60M microscope was used to capture the images of the through-thickness side edge of the un-fractured specimen to observe the barely visible damage on the specimen surface. Image-Pro Plus software was used to analyse the microscopic images that were captured. Interlaminar damage developed in the large-deflection dynamic bending is presented in micrograph of Figure 5. The main mode of damage is delamination along the specimen's longitudinal axis that was expected due to high in-plane shear stresses. At this stage of loading, weft-yarn cracking (intra-ply delamination) can also be observed in the micrograph shown in Figure 6. Here, it can be observed that damage initiation occurred at the weft-yarn edge (crimp location) and then propagated into the weft yarn. Some of these damage modes, e. g. delamination, are incorporated in our FE models.

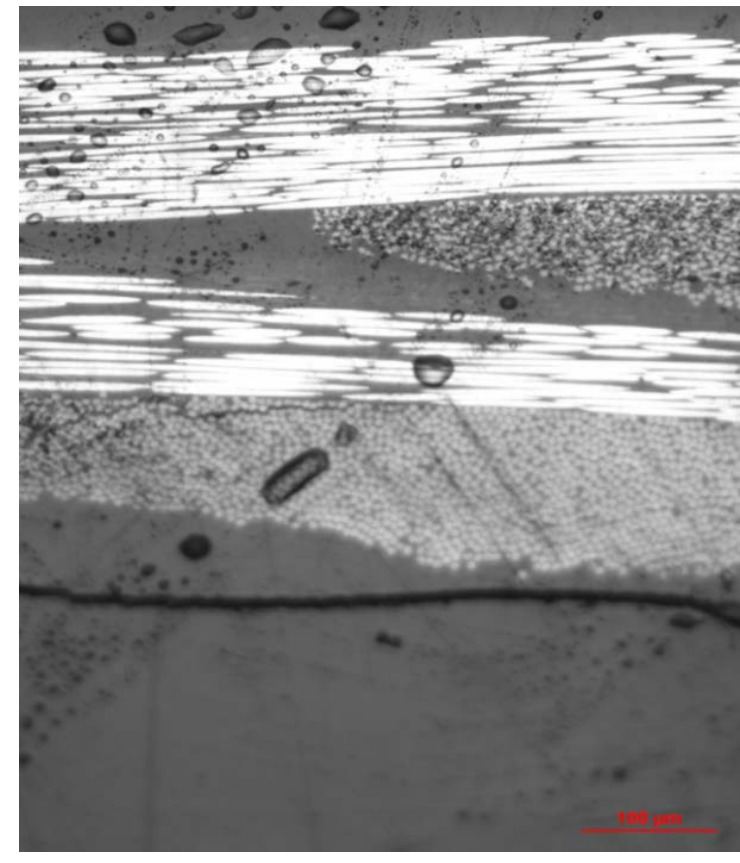

Figure 5. Inter-ply delamination in CFRP laminate

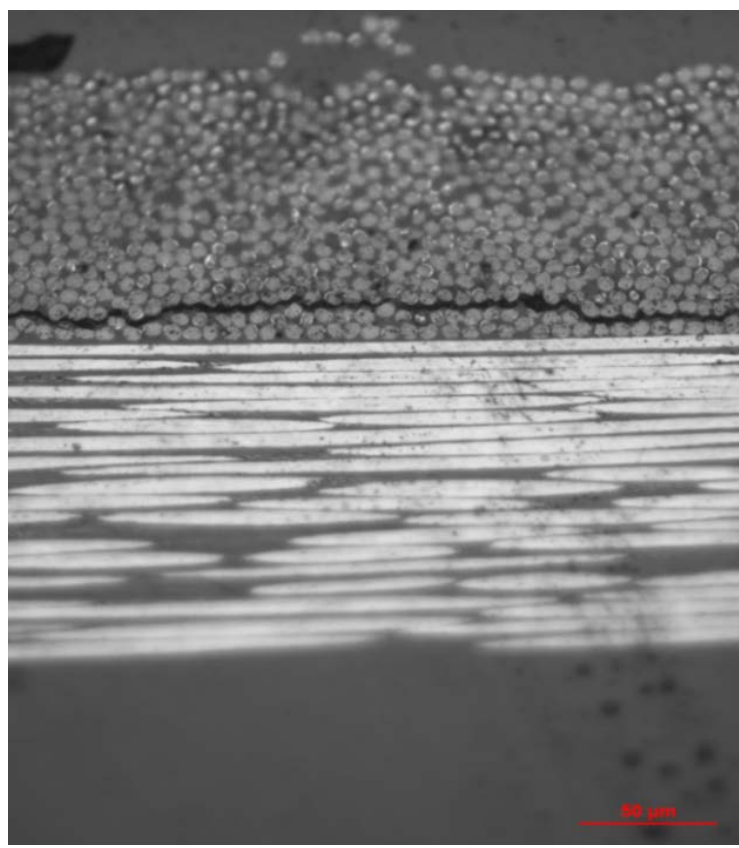

Figure 6. Intra-ply delamination in weft tow in CFRP laminate

\subsection{X-ray micro Computed Tomography analysis of IF specimens}

Inter-ply and intra-ply damage initiation and progression scenarios were assessed with X-ray micro Computed tomography (mCT) for a single sample after specific stages in its IF life to describe the realisation of damage scenarios for various numbers of impacts. During testing it was observed that:

- $\quad$ initiation of axial splits occurred at 4000 impacts;

- inner delaminations at the hole edge appeared at 15000 impacts;

- free-edge delaminations initiated at 18000 impacts; 
- free-edge delaminations propagated along the length of the specimen at 30000 impacts;

- intra-ply cracks localised in the gauge section at 32700-33000 impacts.

From Figures 7 and 8, which present the state of the specimens at the last stages of damage, it can be suggested that the increase in the time response with IF history could be related with the initiation of free-edge delaminations, appearing after a half-life of the specimen

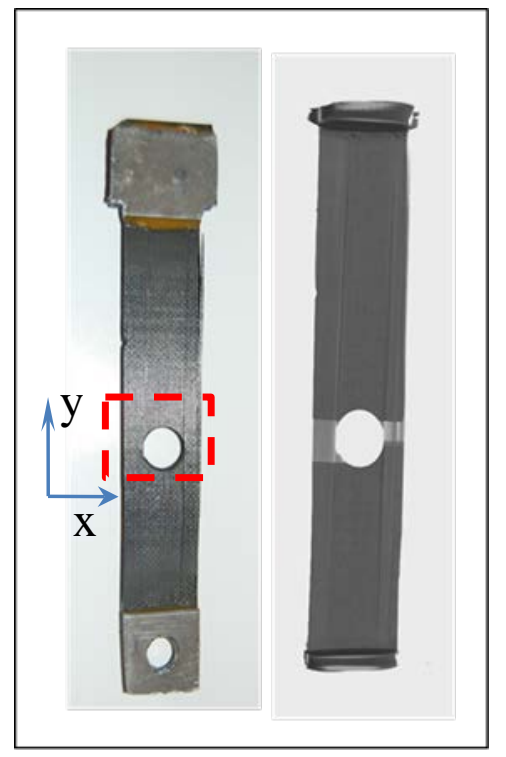

Figure 7. (a) Macroscopic evaluation with (arrows denote slicing directions); (b) semi-transparent $\mathrm{X}$-ray front view of whole specimen at final stage of damage.

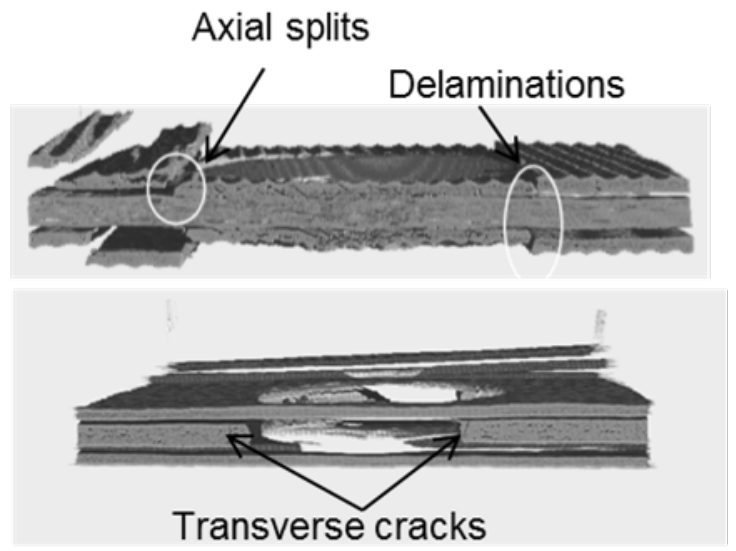

Figure 8. X slices (a) and Y slices (b) at final stages of damage

\section{FINITE-ELEMENT MODELLING}

\subsection{Modelling impact of woven laminates}

Finite-element models were developed in the commercial FE package ABAQUS/ Explicit to investigate large-deflection dynamic bending of tested composite laminates and the resulting inter-ply damage. Two FE models - Models A and B - were developed representing the impact tests on, respectively, un-fractured and fractured $40 \mathrm{~mm}$ long, $25 \mathrm{~mm}$ wide and $1 \mathrm{~mm}$ thick CFRP laminates. The modelled geometry of Model A is shown in Figure 9 along with mesh and boundary conditions. This model was developed first to validate the dynamic contact behaviour of the hammer and specimen without incorporating any damage into simulations. The hammer was discretised with 4-noded linear tetrahedron C3D4 elements, whereas the specimen was meshed with 8-noded linear brick C3D8R elements using a structured meshing technique. These reduced-integration elements are capable of controlling hourglass and eliminating shear locking in bending-dominated problems. Each ply of the laminate was modeled with a single element through its thickness. 
In Model B representing the impact test for impact energy of $0.6 \mathrm{~J}$, cohesive-zone elements were introduced at the interface between the laminate's plies based on delamination observed in the microscopy of the specimen. Three layers were inserted between coincident nodes at the ply interfaces of the studied laminate. Elastic as well as damage properties of interlaminar cohesive layers presented in Table 2 can be found in the previous work of the authors [10]. The surface-to-surface kinematic contact algorithm with finite sliding available in ABAQUS/Explicit was used to simulate contact between the rigid hammer's striking nose and the laminate's surface. The impactor's striking surface and specimen's surfaces were defined as master and slave surfaces, respectively, in the model. A node at the pivot point of the hammer along the axis of rotation was created and then tied with the hammer's cylindrical pivot surface through tie constraints. All translations and rotations of the pivot node were constrained except rotation about z-axis to simulate the hammer's centre of rotation. In the FE models, the initial position of the hammer's striking nose was just in contact with the specimen to avoid the computational cost of bringing the hammer from its inclined position in tests. Initial angular velocities of $5.33 \mathrm{rad} / \mathrm{s}$ and $5.81 \mathrm{rad} / \mathrm{s}$ were applied to the whole hammer, corresponding to the impact energies of $05 \mathrm{~J}$ and $0.6 \mathrm{~J}$ in Models A and B, respectively. All the degrees of freedom of the specimen's bottom were constrained to replicate its boundary conditions in the vice.

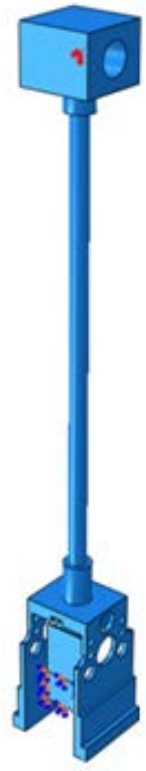

(a)

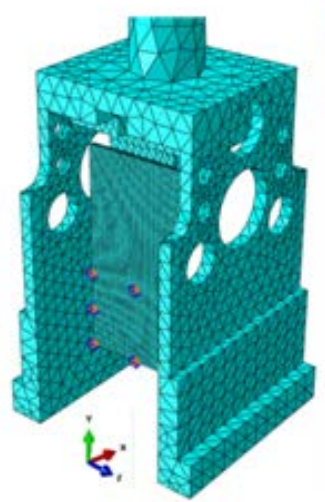

(b)

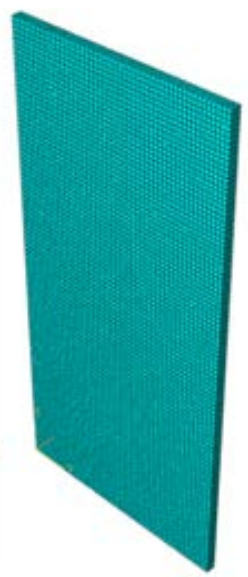

(c)

Figure. 9. Impact test model (a); hammer-specimen contact interaction (b); mesh of specimen (c)

\subsubsection{Interlaminar damage modelling}

Intralaminar damage in Model B for $\mathrm{J}$ impact energy of 0.6 was modeled using cohesive-zone elements (CZEs). CZEs have the ability to capture the onset and propagation of delamination $[10,15,16]$. The cohesive behaviour assumes that failure of elements is 
characterized by progressive degradation of the material stiffness, which is driven by a damage process. Interlaminar damage modes in composite laminates initiate and propagate under the combined influence of normal and shear stresses. The nominal quadratic stress criterion was used for damage initiation. Damage propagation was based on the criterion proposed by Benzeggah and Kenane [17] :

$$
G_{\mathrm{c}}=G_{\mathrm{Ic}}+\left(G_{\mathrm{II} c}-G_{\mathrm{Ic}}\right)\left[\frac{G_{\mathrm{S}}}{G_{\mathrm{T}}}\right]^{\prime \prime}
$$

where $G_{\mathrm{T}}$ is the work by the interface tractions; $G_{\mathrm{S}} / G_{\mathrm{T}}$ is the fraction of cohesive energy dissipated by shear tractions; $G_{\mathrm{S}}$ is the work done by the shear components of interface tractions; $G_{\text {Ic }}$ and $G_{\text {IIc }}$ are critical energy release rates in modes I and II, respectively, and $\eta$ is the material mode-mixity parameter. The damage-initiation and fracture-toughness parameters presented in Table 1 were used in FE Model B. The interface element stiffness was based on the approach by Daudeville et al. [18], which defined the interface stiffness as $K=E_{33} / t_{i}$, where $E_{33}$ is the material's through-thickness stiffness and $t_{i}$ is the thickness of the resinrich interface between plies. Based on this relation, the value of interface stiffness of $4 \times 10^{6}$ $\mathrm{N} / \mathrm{mm}^{3}$ was used in this study, assuming interface thickness of $10 \mu \mathrm{m}$. The application of CZE requires a fine spatial discretization at the cohesive zone to capture the damage growth properly. The number of elements $N_{e}$ in the cohesive-zone is determined according to $N_{e}=l_{c z} / l_{e}$, given in [15], where $l_{c z}$ is the length of cohesive-zone and $l_{e}$ is the mesh size in the direction of crack propagation. Cohesive elements of size $0.3 \mathrm{~mm} \times 0.3 \mathrm{~mm}$ with thickness of $10 \mu \mathrm{m}$ were defined for computationally effective simulations of damage in our numerical Model B.

Table 2. Material properties of CFRP considered in FE model

\begin{tabular}{lrlr}
\hline \multicolumn{2}{c}{ Elastic properties } & \multicolumn{2}{c}{$\begin{array}{c}\text { Interlaminar strength and } \\
\text { toughness }\end{array}$} \\
\hline$E_{11}=E_{22}(\mathrm{GPa})$ & 44.7 & $\sigma_{\mathrm{I} 0}(\mathrm{MPa})$ & 12 \\
$E_{33}(\mathrm{GPa})$ & 8.0 & $\sigma_{\mathrm{II} 0}(\mathrm{MPa})$ & 26 \\
$G_{12}(\mathrm{GPa})$ & 4.4 & $G_{\mathrm{Ic}}\left(\mathrm{J} / \mathrm{m}^{2}\right)$ & 800 \\
$G_{13}=G_{23}(\mathrm{GPa})$ & 3.0 & $G_{\text {IIc }}\left(\mathrm{J} / \mathrm{m}^{2}\right)$ & 1750 \\
$v_{12}$ & 0.05 & & \\
$v_{13}=v_{23}$ & 0.3 & & \\
\hline
\end{tabular}

\subsubsection{Discussion of results}

Results of experimental tests and numerical simulations for the large-deflection dynamic bending behaviour of woven CFRP laminates are presented in this section. The load - time response calculated with our numerical Model A of woven CFRP is compared with the respective experimental curve of un-fractured specimen in Figure 10. The load peak in the FE model is slightly higher than the experimental one. This discrepancy may be due to the fact that the FE model did not take into account real-life energy losses due to material viscous damping and friction between the interacting parts of the experimental setup. However, the contact duration is almost the same implying that the stiffness of the impacted specimen was 
accurately modelled. Variation of kinetic (impact) and strain energy with time for the whole FE model is presented in Figure 11. As it is evident, at the start of impact event, kinetic energy is maximum and the strain energy is minimum. Gradually, the kinetic energy is imparted to the specimen and its strain energy increases. As no damage is incorporated in Model A, so no energy loss can be observed in Figure 11. The force-time response of FE Model B, which incorporated only delamination damage, is presented in Figure 12. Delamination initiation is represented by a first load drop at about $2 \mathrm{~ms}$; delamination progresses as the load increases. Maximum damage can be seen in Figure 13 at about $6.5 \mathrm{~ms}$ where the impact force reaches its peak. In this simulation, delamination initiated first at the point of hammer impact and then initiated at the bending location of the cantilevered CFRP specimen.

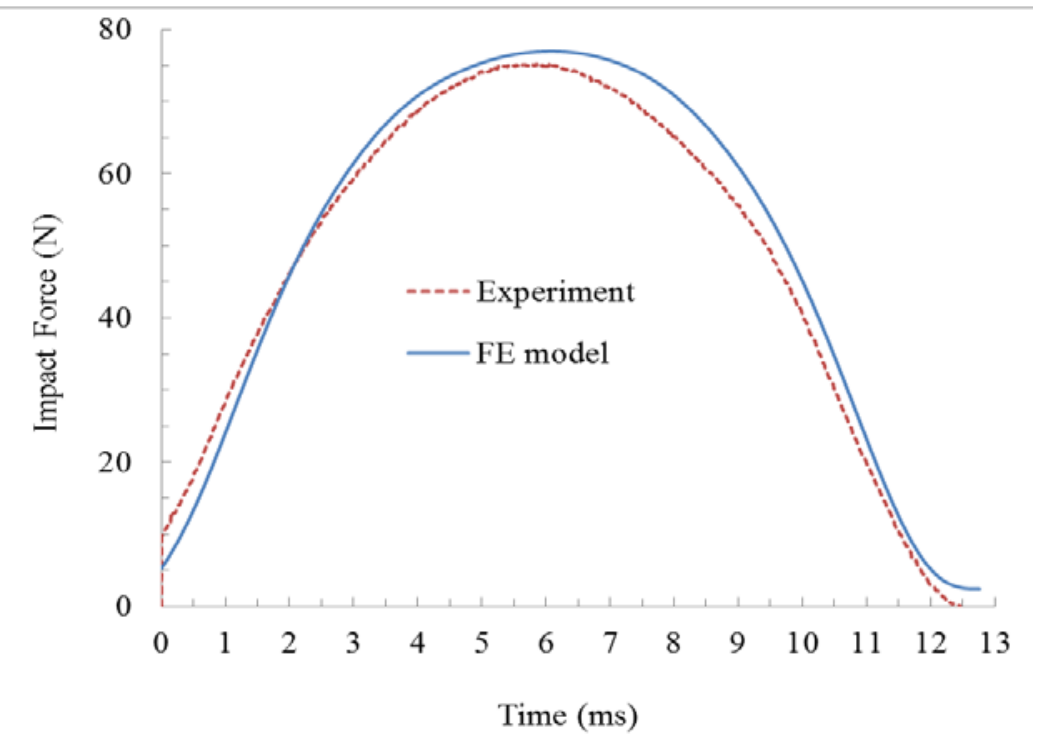

Figure 10. Comparison of experimental and numerical results in terms of force-time response of CFRP woven laminates at $0.5 \mathrm{~J}$ impact energy

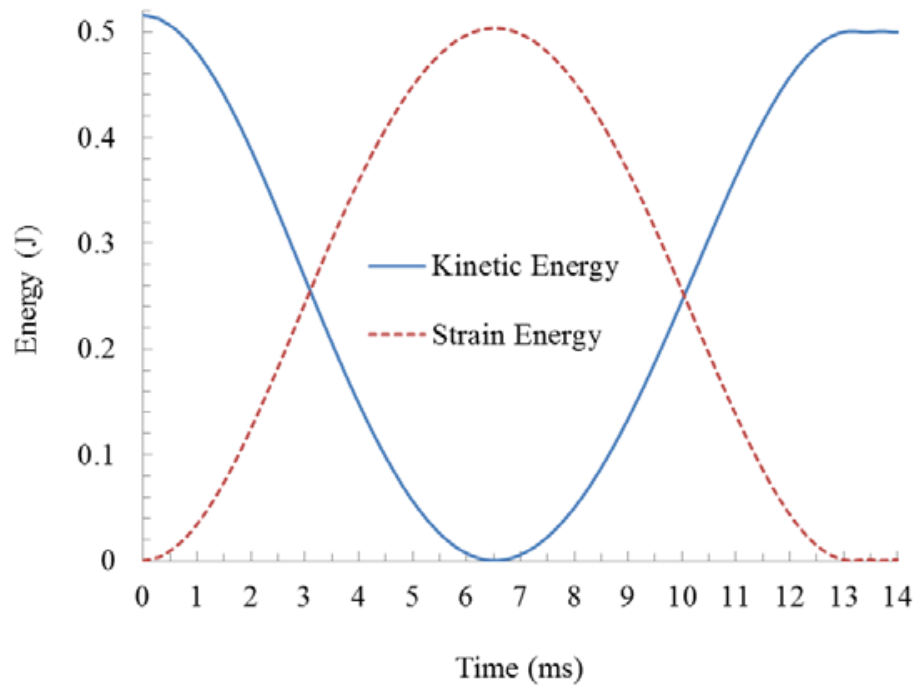

Figure 11. Variation of kinetic and strain energy with time for woven CFRP laminate in undamaged Model A 


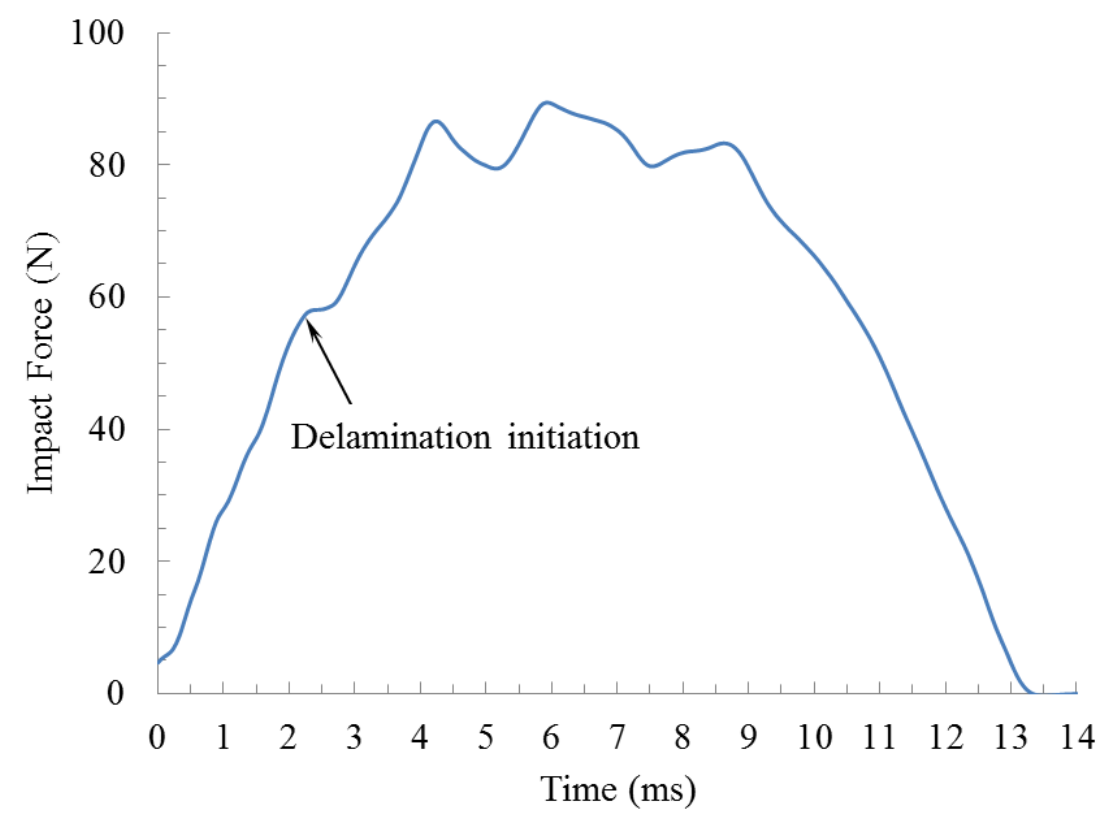

Figure 12. Force vs. time response of FE Model B of woven CFRP laminate incorporating delamination damage at $0.6 \mathrm{~J}$ impact energy

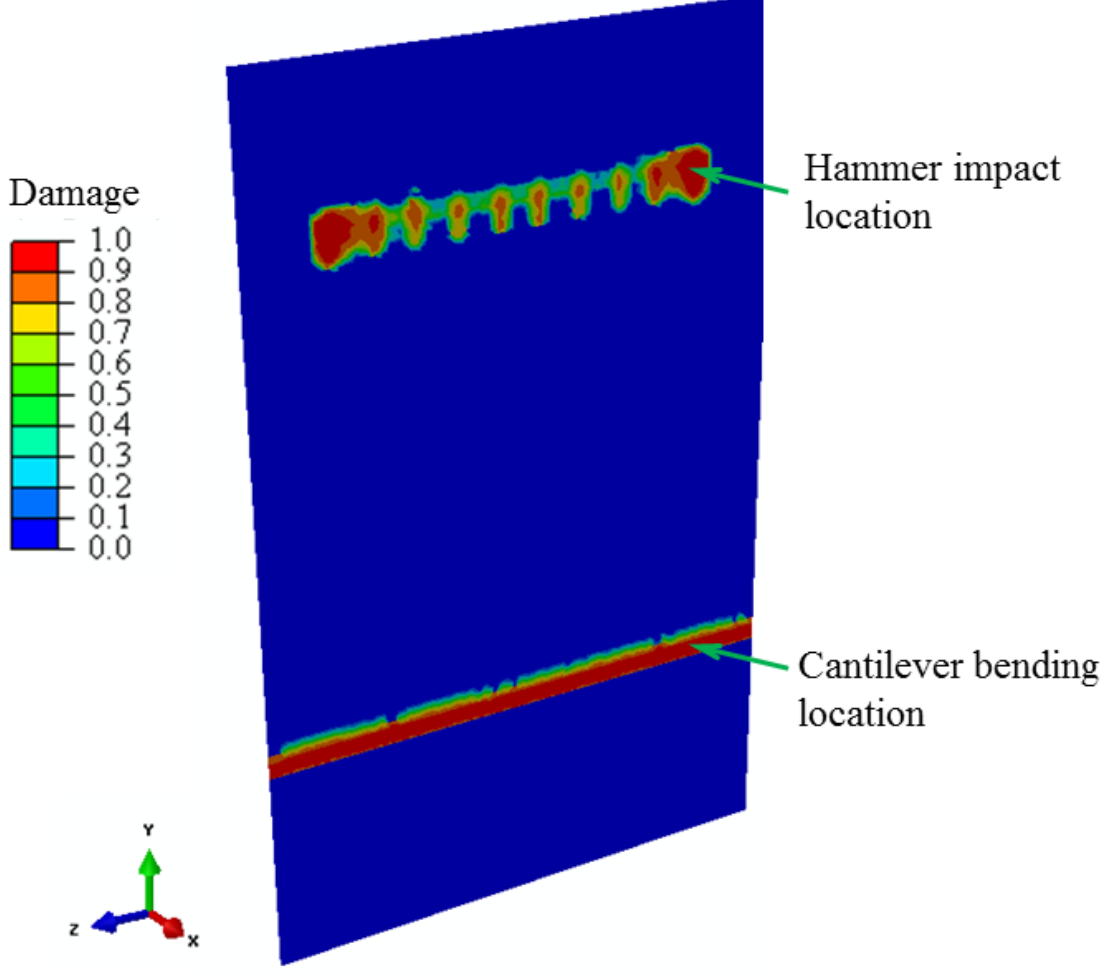

Figure 13. Interlaminar delamination damage in Model B of woven CFRP laminate at $0.6 \mathrm{~J}$ impact energy 


\subsection{Cross-ply CFRP laminates: Modelling and results}

Single-impact results revealed successful modelling of cross-ply CFRP composite laminates identifying areas of stress concentration as seen in Figure 14. Furthermore, the calculated force- time response is in good agreement with the experiment as shown in Figure 15. This is the first step in development of simulation procedures for modelling multiple impacts with the use of CZE. An important problem here is a selection of the CZE properties; a quasi-static model was built for that reason. The obtained results revealed that the stiffness was matching that observed in our experiments, and realisation of damage progression scenarios was satisfying. In Figures 16 and 17, a model of one-quarter symmetric portion of the central-hole section is shown. Cohesive-zone elements were placed in areas where matrix cracks, axial splits and delaminations were observed experimentally. The main stages of damage progression scenarios are as follows:

1. Isolated damage at the hole edge due to matrix cracking in the 90 degree plies. It was accompanied by inner delamination at the interfaces at $45^{\circ}$ and $-45^{\circ}$ from the centre of the hole propagating towards the middle of the hole in a clockwise manner as seen in Figure 17b. Such delamination occurred as a result of free edges and matrix cracks produced by high interlaminar normal and shear stresses generated in that region.

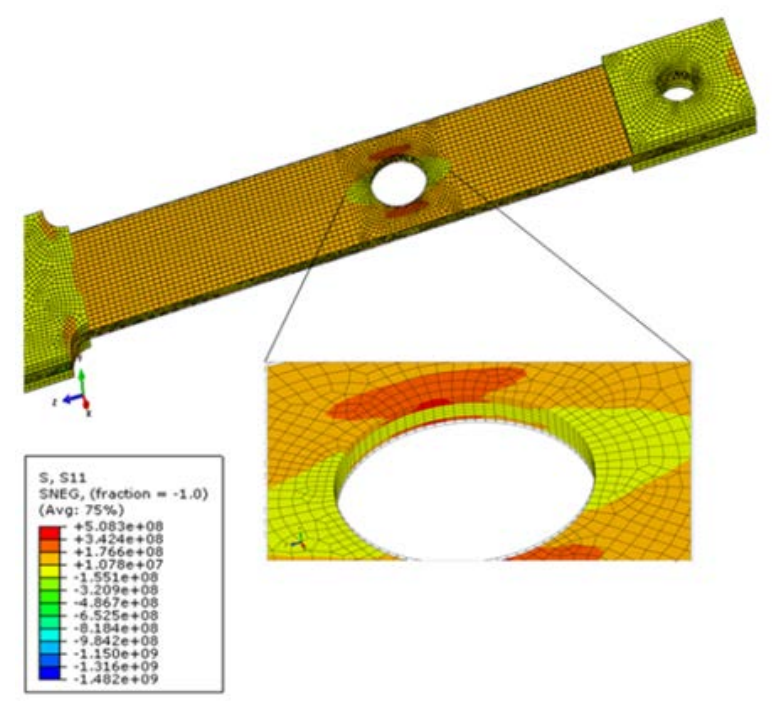

Figure 14. Principal stress contour in loading direction that indicate damage initiation in top and bottom 0 degrees plies as well as delamination initiation at 0/90 and 90/0 interfaces

2. Almost simultaneous generation of $0^{\circ}$ splits occurred that increased in length in either way with increasing number of impacts but was always adjacent to the hole. Figure 17c highlights these events.

3. Damage propagated across the width of the specimen in the form of delamination (Figure 17d). As loading continued, delamination at the hole and specimen's free edge propagated towards each other. When they became close, delamination though the entire specimen's 
width occurred. Final catastrophic failure occurred when intra-ply matrix cracks propagated fully through the thickness and width of the gauge section, resulting in a complete removal of the $90^{\circ}$ ply at the gauge area.

\section{CONCLUSIONS}

The dynamic behaviour of woven CFRP laminates under large-deflection bending was studied using experimental tests and numerical simulations, while cross-ply laminates were investigated for conditions of impact fatigue. Both types of tests demonstrated complex scenarios of spatio-temporal evolution of multiple damage modes in laminates. Those modes were studied by means of microscopic analysis (optical and mCT). Identification of areas of localisation of different damage modes was used for introduction of cohesive-zone elements into finite-element models used to simulate responses of the studied laminates to various

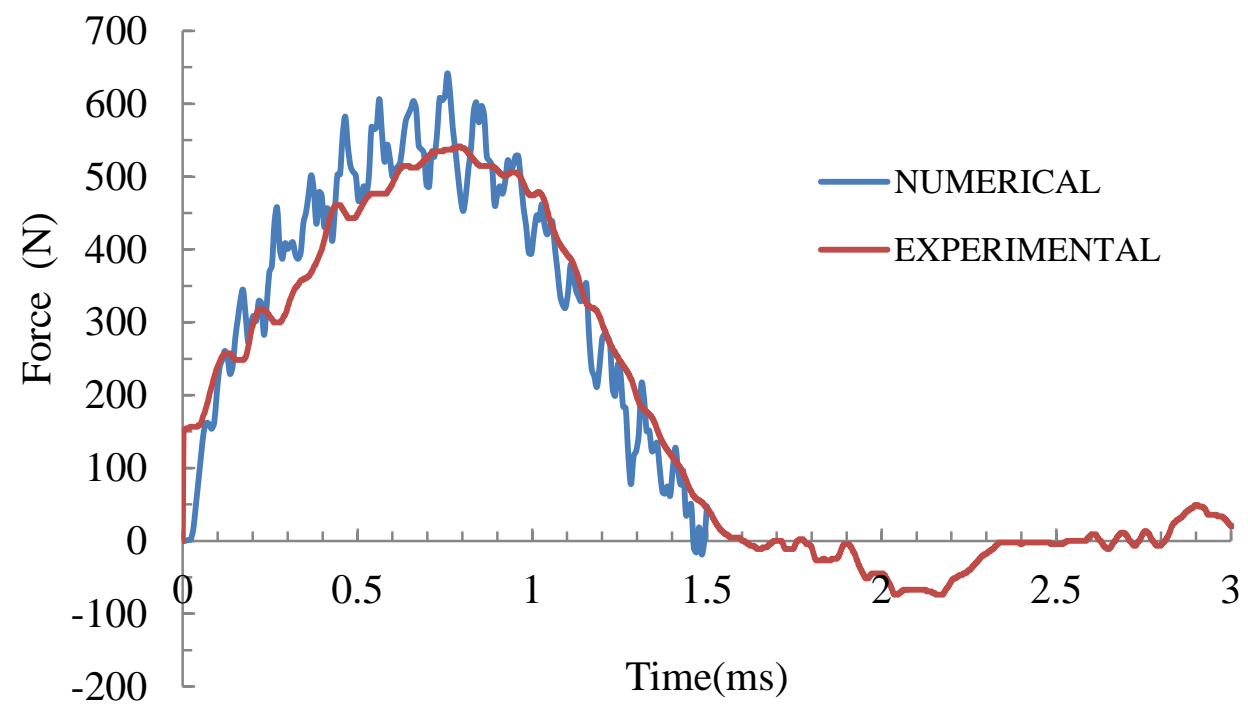

Figure 15. Comparison of impact force history for experimental data and numerical analyses

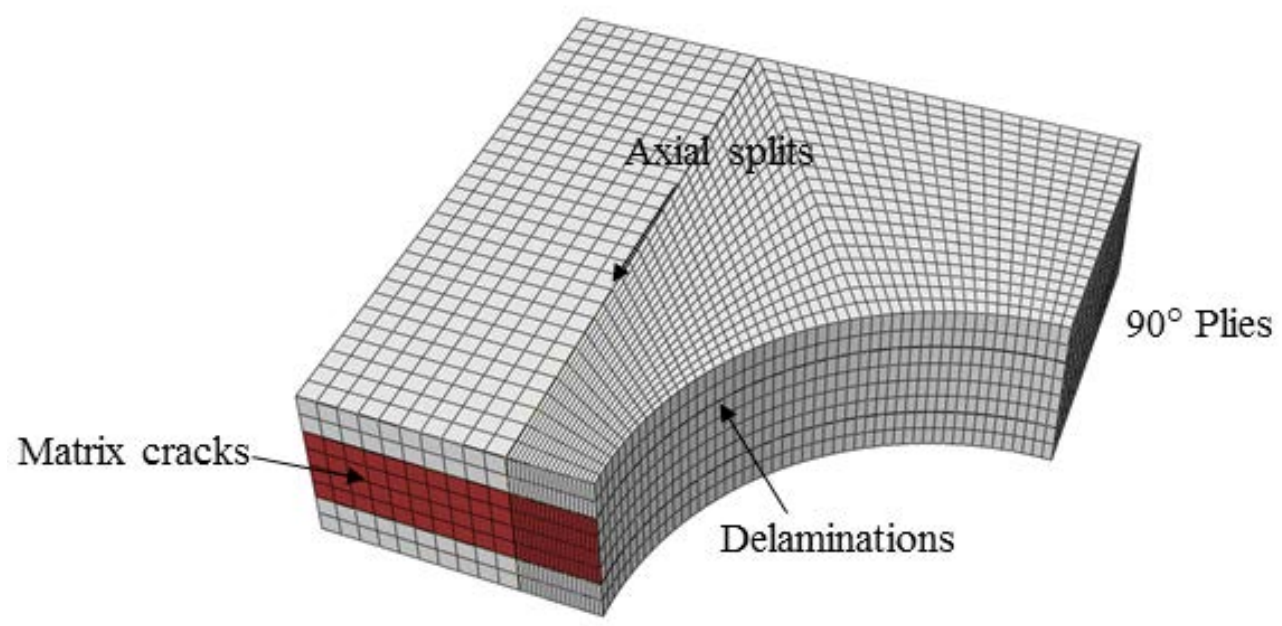

Figure 16. One-quarter model of central section of specimen. Individual partitions for insertion of CZE are shown for each different damage mode. 
loading conditions. The developed models helped to gain a better understanding of the multibody impact dynamics in dynamic loading of composite specimens. The obtained numerical results were in agreement with experimental data and thus validated the modelling approaches for the dynamic events. The next step will be a further development of the models to incorporate, on the one hand, multiple damage modes and their interaction in ones, dealing with dynamic bending of woven-fabric reinforced laminates, and, on the other hand, accounting for cumulative result of multiple impacts on cross-ply laminates in simulations for impact fatigue.

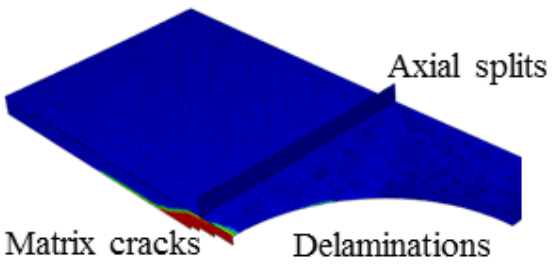

(a)

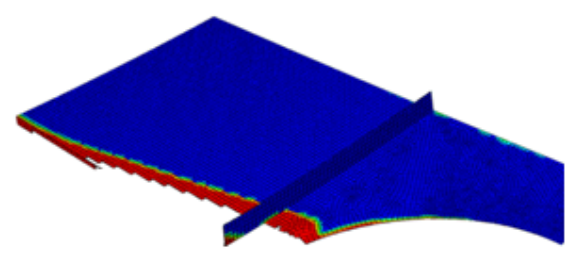

(c)

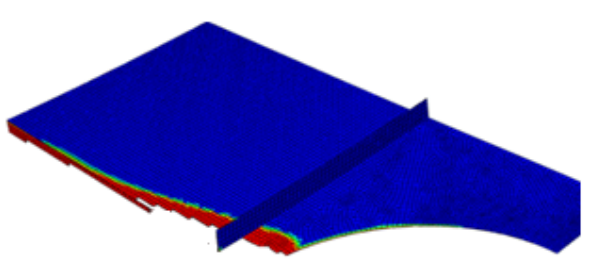

(b)

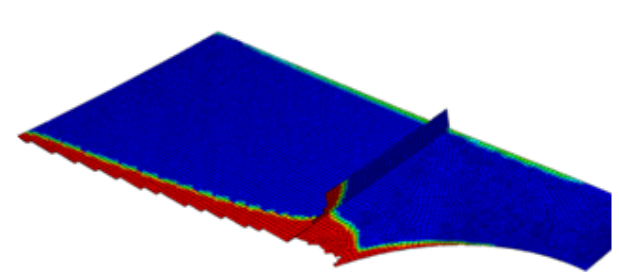

(d)

Figure 17. Isolated CZE sections highlighting damage progression in notched area

\section{REFERENCES}

[1] Ernst G., Vogler M., Hühne C., Rolfes R., "Multiscale progressive failure analysis of textile composites”. Compos. Sci. Technol.. 70(1), 61-72, 2010.

[2] Menna C., Asprone D., Caprino G., Lopresto V., Prota A., "Numerical simulation of impact tests on GFRP composite laminates”. Int. J. Impact Eng.. 38(8-9), 677-85, 2011.

[3] Casas-Rodriguez J., Ashcroft I. A., Silberschmidt V. V., "Damage in adhesively bonded CFRP joints: Sinusoidal and impact-fatigue”. Compos. Sci. Technol.. 68(13), 2663-70, 2008.

[4] Casas-Rodriguez J., Ashcroft I. A., Silberschmidt V. V., "Delamination in adhesively bonded CFRP joints: Standard fatigue, impact-fatigue and intermittent impact”. Compos. Sci. Technol.. 68(12), 2401-9, 2008.

[5] Abrate S. "Modeling of impacts on composite structures". Compos. Structures. 51(2), 129-38 2001. 
[6] Naik N., Chandra Sekher Y., Meduri S., "Damage in woven-fabric composites subjected to low-velocity impact”. Compos. Sci. Technol.. 60(5), 731-44, 2000.

[7] Johnson A., Pickett A., Rozycki P., "Computational methods for predicting impact damage in composite structures”. Compos. Sci. Technol. 61(15), 2183-92, 2001

[8] Iannucci L., Willows M., “An energy based damage mechanics approach to modelling impact onto woven composite materials--Part I: Numerical models”. Compos. A 37(11), 2041-56, 2006.

[9] Reyes G., Sharma U., "Modeling and damage repair of woven thermoplastic composites subjected to low velocity impact. Compos. Structures. 92(2), :523-31, 2010.

[10] Ullah H., Harland A. R., Lucas T., Price D., Silberschmidt V. V., "Finite-element modelling of bending of CFRP laminates: Multiple delaminations”. Comput. Mater. Sci.. 52(1):147-56, 2012.

[11] Ullah H., Harland A. R., Lucas T., Price D., Silberschmidt V. V., “Analysis of nonlinear deformations and damage in CFRP textile laminates”. J. Phys.: Conf. Ser. 305, 12045, 2011.

[12] Ullah H., Harland A. R., Blenkinsopp R., Lucas T., Price D., Silberschmidt V. V., "Analysis of nonlinear shear deformations in CFRP and GFRP textile laminates". Appl. Mech. Mater. 70, 363-8, 2011.

[13] Silberschmidt V. V. , Casas-Rodriguez J. P., Ashcroft I. A., "Impact fatigue of adhesive joints”. Key Eng. Mater. 399, 71-8, 2009.

[14] Daggumati S., Voet E., Van Paepegem W., Degrieck J., Xu J., Lomov S. V., et al. "Local strain in a 5-harness satin weave composite under static tension: Part I Experimental analysis”.Compos. Sci. Technol. . 70, 1926-33, 2010.

[15] Turon A., Davila C. G., Camanho P. P., Costa J., "An engineering solution for mesh size effects in the simulation of delamination using cohesive zone models". Eng Fracture Mech.. 74(10), 1665-82, 2007.

[16] Ullah H., Harland A. R. , Silberschmidt V. V., "Experimental and numerical analysis of damage in woven GFRP composites under large-deflection bending”. Appl. Compos. Mater. DOI: 10.1007/s10443-011-9242-7.

[17] Benzeggagh M. L., Kenane M., "Measurement of mixed-mode delamination fracture toughness of unidirectional glass/epoxy composites with mixed-mode bending apparatus". Compos. Sci. Technol.. 56(4), 439-49, 1996.

[18] Daudeville L., Allix O., Ladeveze P., "Delamination analysis by damage mechanics: some applications”. Compos. Eng.. 5(1), 17-24, 1995. 